\title{
Imported Inputs and the Gains from Trade*
}

\author{
Ananth Ramanarayanan \\ University of Western Ontario \\ February, 2012 \\ PRELIMINARY AND INCOMPLETE
}

\begin{abstract}
The bulk of international trade takes place in intermediate inputs as opposed to goods for final consumption. Studies of firm-level data show that there is substantial heterogeneity in the share of inputs that are imported by different firms, and that a firm's productivity increases with the quantity and variety of inputs that it imports. This paper develops a model to quantify the contributions of firm-level productivity gains to aggregate productivity and welfare gains from trade. In the model, heterogeneous firms choose the fraction of their inputs to import. Importing a higher fraction of inputs raises firm-level productivity, but requires higher up-front fixed costs. Therefore, firms with different inherent profitability will vary in how much they import and the productivity they gain from doing so. This heterogeneity provides aggregate productivity and welfare gains from trade that would not exist in a world in which firms used identical input bundles. These gains are consistent with data on specific trade liberalization episodes that show large firm-level productivity gains attributed to higher imports of intermediate inputs.
\end{abstract}

*Contact: Department of Economics, University of Western Ontario, Social Science Centre, Room 4071, London, Ontario, Canada, N6A 5C2. Email: ananth.ramanarayanan@gmail.com. 


\section{Introduction}

Intermediate inputs comprise about half of international trade in goods for most industrialized countries, and international trade theory has for a long time dealt explicitly with goods used in production as distinct from trade in goods for final consumption. ${ }^{1}$ In addition, models of trade in intermediate inputs have been useful in studying the relationship between trade and growth. ${ }^{2}$ Until recently, the bulk of this work has been based on models in which all producers use an identical bundle of imported and domestic goods. However, a recent literature examining firm- and plant-level data has found that imported inputs are concentrated among relatively few producers, and there is substantial heterogeneity in import shares among them. ${ }^{3}$ Understanding the producer-level decisions behind these outcomes is important for understanding the behavior of trade in intermediate goods at the aggregate level and how the gains from importing these goods are distributed across different producers.

This paper develops a model of trade in intermediate goods in which heterogeneous plants decide on how much of their inputs to import. In the model, plants use a continuum of intermediate inputs, any of which can be imported. Imported inputs are cheaper, and so a plant's productivity is increasing in the share of goods it imports, but there is cost of raising the number of goods imported. Plants differ in their underlying efficiency, and more efficient plants choose to import a higher share of their inputs, while the least efficient choose to not import at all. Importing plants, therefore, are larger and more productive, both because they take advantage of the productivity gains of importing, and because they tend to be more efficient producers. The model generates cross-sectional dispersion in import shares and plant size, which depends on the parameters governing underlying heterogeneity and the benefits and costs of importing. I calibrate the model to match moments of the distributions of these variables among manufacturing plants in Chile, and then analyze the response of plant-level and aggregate productivity and trade flows to shocks that change the price of imports relative to domestic inputs.

The model can account for the large within-plant productivity gains following trade liberalization found, for example, by Amiti and Konings (2007) in Indonesian manufacturing firms after tariffs were reduced in the mid 90s. In my model, as the relative price of imports falls, plants raise the share of inputs they import, taking advantage of higher cost savings, which increases the effective productivity with which they produce output. This productivity

\footnotetext{
${ }^{1}$ Trade in intermediate goods plays a role in, among others, Sanyal and Jones (1982), Ethier (1982), Krugman and Venables (1995), and Eaton and Kortum (2002).

${ }^{2}$ See, for example, Grossman and Helpman (1990) and Rivera-Batiz and Romer (1991).

${ }^{3}$ Kasahara and Lapham (2007) have documented these facts for Chile, while similar facts can be found in Kurz (2006) and Bernard, Jensen, and Schott (2009) for the US, Biscourp and Kramarz (2007) for France, Amiti and Konings (2007) for Indonesia, and Halpern, Koren, and Szeidl (2009) for Hungary.
} 
gain is quantitatively similar in magnutide to that estimated by Amiti and Konings (2007).

A literal interpretation of the production technology in my model is that imports are perfect substitutes for domestic inputs, but are available at a lower cost, so that importing a larger share lowers the average cost of production. More broadly, imported inputs could also yield productivity gains because imports are of higher quality than comparable domestic inputs, or because imported goods are imperfect substitutes for domestic goods. The quality story, for example discussed in Grossman and Helpman (1991), is studied in plant-level data for Mexico by Kugler and Verhoogen (2009). Imperfect substitutability would generate gains from input variety as in Ethier (1982) and Romer (1990). Halpern, Koren, and Szeidl (2009) use data on the number of goods Hungarian firms import to measure the relative magnitudes of the quality and substitutability channels. Goldberg, Khandelwal, Pavcnik, and Topalova (2010) also measure the benefits of input variety using data on Indian firms, though they measure the effects on the number of products firms produce, not on their productivity. Using data from Argentina, Gopinath and Neiman (2011) show that the adjustment of the number of inputs firms import accounts for high-frequency movements in productivity. In a model that combines the decisions to import and export, Kasahara and Lapham (2007) assume plants gain from importing through the variety effect, but the number of imports each importing plant uses is fixed.

The fixed costs of importing in my model are meant as a stand-in for costs of using imported goods that do not depend on the amount purchased. These can include the costs of finding suppliers, or the costs of testing and finding out whether an imported product is an appropriate substitute for a domestic one. In my model, fixed costs are necessary to get the result that only some plants import, and the shape of the fixed cost as a function of the share of inputs imported generates the differences in import shares observed in the data. These results follow in the same way that models of producers' decisions to export, such as those in Melitz (2003) and Chaney (2008) have used fixed costs to segment firms into exporters and nonexporters. The form of the fixed costs of importing I use generates a profit maximization problem at the plant level that shares features of the model in Arkolakis (2008), in which a producer pays an increasing cost to export to a larger fraction of consumers.

Section 2 below sets out the model. Section 3 shows how parameters relate to the cross-sectional distribution of import shares and plant size under a Pareto distribution for exogenous plant-level efficiency. In this section, I also perform counterfactual exercises to evaluate the model's response to a trade liberalization. 


\section{Model}

The model consists of a small open economy in which heterogeneous plants produce output using a continuum of intermediate goods and labor. These plants differ in their exogenous productive efficiency. The time horizon is infinite and discrete and the date is indexed by $t=0,1, \ldots$ Over time, plants are subject to a constant probability of death, and new plants enter. A representative household owns all the plants, supplies them labor, consumes their output, and decides how many new plants to create each period.

Intermediate goods are labeled $\omega \in[0,1]$, but I assume that the technologies for producing these goods are identical. Any intermediate good can be produced domestically with one unit of the final output, or can be imported at the price $p_{t}<1$, which is exogenous. In the quantitative results, I consider steady state equilibria of the model in which $p_{t}$ is constant. Domestic intermediate goods are produced by a perfectly competitive sector with constant returns to scale, so that they have a price of 1 . The rest of the model description below focuses entirely on the decisions of final goods plants, with the production of intermediate goods playing a background role.

Imported goods have a lower per-unit cost, and so importing rather than using domestic goods gives a plant higher profits; however, a plant must pay a fixed cost per period that is rising in the number of goods it imports. At any point in time, high productivity plants find it more profitable to import a relatively large fraction of goods.

\subsection{Plants' Problem}

Each period, an existing plant chooses the fraction of goods to import and the quantities of labor and imported and domestic goods to use in production. I first describe a plant's technology and consider its decisions given the fraction of goods it imports, then turn to the problem of choosing the optimal fraction of goods to import.

A plant with productivity $z$ that imports the fraction $n \in[0,1]$ of its inputs produces output $y$ according to the technology

$$
y=z^{1-\alpha-\theta} \ell^{\alpha}\left(\exp \left(\int_{0}^{n} \log m(\omega) d \omega+\int_{n}^{1} \log x(\omega) d \omega\right)\right)^{\theta}
$$

where $\ell$ is labor, and $m(\omega)$ and $x(\omega)$ are the quantities of each imported and domestic intermediate input the plant uses. These inputs are combined in a Cobb-Douglas fashion. Without loss of generality, I assume that a plant imports the first $n$ goods in the range $[0,1]$. The parameters $\alpha, \theta \in(0,1)$ determine expenditure shares on labor and intermediate goods, and $\alpha+\theta<1$. 
The production function here is a simplified version of the one considered in Goldberg, Khandelwal, Pavcnik, and Topalova (2010) and Halpern, Koren, and Szeidl (2009). The main difference is that in their specification, imported goods are only imperfect substitutes for domestic goods, so that the first $n$ inputs are composed of a composite of the imported and domestic version. The technology is also related to the one used Kasahara and Lapham (2007), in a model in which all importing plants import the same fraction of goods.

Since imported goods all have price $p_{t}$ and domestic goods all have price 1, plants will purchase all imported goods in the same quantity, and all domestic goods in the same quantity. That is, I can restrict attention in the plant's problem to $m(\omega)=m$ for all $\omega \in[0, n]$ and $x(\omega)=x$ for all $\omega \in(n, 1]$. Then, the plant's technology can be written:

$$
y=z^{1-\alpha-\theta} \ell^{\alpha}\left(m^{n} x^{1-n}\right)^{\theta}
$$

The plant's variable profit at date $t, \tilde{\pi}_{t}(z, n)$ is:

$$
\tilde{\pi}_{t}(z, n)=\max _{\ell, m, x} z^{1-\alpha-\theta} \ell^{\alpha}\left(m^{n} x^{1-n}\right)^{\theta}-w_{t} \ell-p_{t} n m-(1-n) x
$$

where $w_{t}$ is the wage rate in units of the domestic final good.

Solving this problem, the inputs that maximize variable profit can be written:

$$
\begin{aligned}
\ell_{t}(z, n) & =z v_{t} \frac{\alpha}{w_{t}} p_{t}^{-\gamma n} \\
x_{t}(z, n) & =z v_{t} \theta p_{t}^{-\gamma n} \\
m_{t}(z, n) & =z v_{t} \theta p_{t}^{-\gamma n-1}
\end{aligned}
$$

where

$$
\gamma=\theta /(1-\alpha-\theta)
$$

and

$$
v_{t}=\left(\theta^{\theta}\left(\frac{\alpha}{w_{t}}\right)^{\alpha}\right)^{1 /(1-\alpha-\theta)}
$$

Maximized profit is given by

$$
\tilde{\pi}_{t}(z, n)=z v_{t} p_{t}^{-\gamma n}(1-\alpha-\theta)
$$

Given $n$, a plant with a higher $z$ is larger in terms of labor, domestic inputs, and imported inputs, and has higher profits.

Since $p_{t}<1$, a higher fraction $n$ of goods imported increases profits and makes a plant 
hire more labor and purchase a larger amount per intermediate input, both for imported and domestically purchased goods, $m_{t}(z, n)$ and $x_{t}(z, n)$. Also, total expenditures on intermediate goods, $p_{t} n m_{t}(z, n)+(1-n) x_{t}(z, n)=z v_{t} \theta p_{t}^{-\gamma n}$, are increasing in $n$, and the share of input expenditures spent on imported goods, $\frac{p_{t} m_{t}(z, n)}{p_{t} m_{t}(z, n)+x_{t}(z, n)}$, is equal to $n$ (from now on, then, I will refer to $n$ as a plant's import share).

If unconstrained, it's clear that a plant would want to choose $n=1$, regardless of its efficiency $z$. To introduce differences in import shares, I assume that a plant that imports $n$ goods must pay a cost in each period of $h(n)=b\left(f^{n}-1\right)$ goods, with $b>0$ and $f>1$. The important features of this cost function are that it is increasing and convex in $n$, so that profits net of the fixed cost of importing can be made concave in $n$. In addition, $h(0)=0$, so that the fixed cost of importing is continuous at 0 .

Call the maximized profit of a plant with productivity $z$, after it has chosen its import share $n, \pi_{t}(z)$ :

$$
\pi_{t}(z)=\max _{n \in[0,1]} \tilde{\pi}_{t}(z, n)-h(n)
$$

I show in the appendix that this problem is characterized by a unique solution $n_{t}(z)$ that takes the following form:

$$
n_{t}(z)=\left\{\begin{array}{c}
0 \text { if } z<z_{t}^{0} \\
\psi_{t} \log z+\phi_{t} \text { if } z \in\left[z_{t}^{0}, z_{t}^{1}\right] \\
1 \text { if } z>z_{t}^{1}
\end{array}\right.
$$

where

$$
\begin{aligned}
\psi_{t} & =\frac{1}{\log f+\gamma \log p_{t}} \\
\phi_{t} & =\psi_{t} \log \left(\frac{v_{t} \theta\left(-\log p_{t}\right)}{b \log f}\right)
\end{aligned}
$$

and the thresholds are defined by $\psi_{t} \log z_{t}^{0}+\phi_{t}=0$ and $\psi_{t} \log z_{t}^{1}+\phi_{t}=1$ :

$$
\begin{aligned}
z_{t}^{0} & =e^{-\phi_{t} / \psi_{t}} \\
z_{t}^{1} & =e^{\left(1-\phi_{t}\right) / \psi_{t}}
\end{aligned}
$$

Under the assumption that $f>0$ and $p_{t}<1$, the sign of $\psi_{t}$ can in general be either positive or negative. However, profit is concave, and (2) characterizes the solution to the profit maximization problem, only if $f>p_{t}^{-\gamma}$, so that $\psi_{t}>0$, which I assume to always be true from here on.

Therefore, looking across plants with different efficiency levels, the optimal import share 
$n_{t}(z)$ is non-decreasing in $z$, is positive only for $z \geq z_{t}^{0}$, and is strictly increasing in the range $\left[z_{t}^{0}, z_{t}^{1}\right]$. Only plants with sufficiently high $z$ are profitable enough to cover the fixed cost of importing at all, and since $f>p_{t}^{-\gamma}, n_{t}(z)$ is non-decreasing in $z$ among importing plants because the benefit of a high import share outweighs the cost only for highly efficient - hence profitable - plants.

\subsection{Household's Problem}

The representative household has preferences over sequences of consumption $C_{t}$ and labor supply $L_{t}$ represented by:

$$
E_{0} \sum_{t=0}^{\infty} \beta^{t} U\left(C_{t}, L_{t}\right)
$$

where $\beta \in(0,1)$ is the household's discount factor, and $E_{0}$ denotes the expectation as of date 0 .

The household receives the profits from all the plants operating in the economy, and invests in creating new plants, by paying a sunk cost $F_{e}$ for each new plant. Each plant operating receives a draw of its efficiency $z$ from a distribution with cumulative distribution function $G(z)$ and density $g(z)$. This efficiency is fixed for the life of the plant. Each

period, every plant is subject to a constant probability $\delta$ of death, so a fraction $\delta$ of plants each period exit.

The budget constraint of the household is therefore:

$$
C_{t}+F_{e} I_{t} \leq w_{t} L_{t}+K_{t} \int_{z_{L}}^{\infty} \pi_{t}(z) g(z) d z
$$

where $K_{t}$ is the mass of operating plants in period $t, I_{t}$ is the mass of new plants the household creates in period $t$, and $w_{t}$ is the wage rate earned on labor supplied. The mass of plants owned by the household evolves according to:

$$
K_{t+1}=(1-\delta) K_{t}+I_{t}
$$

The household's problem is to maximize (3) subject to (4) and (5) for all $t$. The first order conditions of this problem yield:

$$
\begin{aligned}
\frac{U_{L t}}{U_{C t}} & =-w_{t} \\
F_{e} U_{C t} & =\beta E_{t} U_{C t+1}\left(\int_{z_{L}}^{\infty} \pi_{t+1}(z) g(z) d z+F_{e}(1-\delta)\right)
\end{aligned}
$$


where $U_{C t}$ and $U_{L t}$ are the partial derivatives of the utility function $U$ with respect to consumption and labor at date $t$, respectively. The first equation in (6) governs the household's labor supply decision, and the second governs the investment decision in new plants, and therefore determines how many new plants enter.

\subsection{Aggregation and Equilibrium}

The total amount of labor, domestic inputs and imported inputs demanded by plants, and their total output are found by aggregating up the individual decisions in (1):

$$
\begin{aligned}
L_{t} & =K_{t} v_{t} \frac{\alpha}{w_{t}} \int_{z_{L}}^{\infty} z p_{t}^{-\gamma n_{t}(z)} g(z) d z \\
D_{t} & =K_{t} v_{t} \theta \int_{z_{L}}^{\infty} z\left(1-n_{t}(z)\right) p_{t}^{-\gamma n_{t}(z)} g(z) d z \\
M_{t} & =K_{t} v_{t} \theta \frac{1}{p_{t}} \int_{z_{L}}^{\infty} z n_{t}(z) p_{t}^{-\gamma n_{t}(z)} g(z) d z \\
Y_{t} & =K_{t} v_{t} \int_{z_{L}}^{\infty} z p_{t}^{-\gamma n_{t}(z)} g(z) d z
\end{aligned}
$$

and the total amount of fixed costs of importing paid by plants is

$$
H_{t}=K_{t} b\left(\int_{z_{L}}^{\infty} f^{n_{t}(z)} g(z) d z-1\right)
$$

An equilibrium consists of sequences $w_{t}, C_{t}, L_{t}, K_{t}, M_{t}, D_{t}, Y_{t}, I_{t}, H_{t}$, and plant-level decisions given by (2) and (1) that satisfy the definitions of the plant-level aggregates in (7)-(11) and the household's first order conditions (6), along with the aggregate feasibility condition:

$$
C_{t}+F_{e} I_{t}+D_{t}+p_{t} M_{t}+H_{t}=Y_{t}
$$

The economy pays for imports $p_{t} M_{t}$ with output of its domestic final goods. The feasibility condition is the same as the household's budget constraint in equilibrium, since

$$
w_{t} L_{t}+K_{t} \int_{z_{L}}^{\infty} \pi_{t}(z) g(z) d z=Y_{t}-D_{t}-\tau_{t} M_{t}-H_{t}
$$

That is, gross output minus inputs minus fixed costs is equal to total wage payments plus total profits. 


\section{Quantitative Analysis}

In this section, I analyze the model's quantitative implications. I consider steady state equilibria in which the price of imports $p_{t}$ is constant. Given a functional form for the distribution $G$, the model generates variation in import shares and plant sizes through the decision rules in (2) and (1). I choose values for several of the model's parameters to match features of the distributions of these variables in Chilean plant level data. I then consider the effects on trade growth and productivity of a unilateral trade liberalization that lowers the price of imports $p_{t}$.

\subsection{Calibration}

I set several parameters in line with the business cycle literature, and choose a subset of the parameters to match statistics in Chilean plant-level data. Table 1 summarizes the parameter values.

I set $\beta=0.96$, which roughly corresponds to a $4 \%$ real interest rate on an annual basis. I assume the utility function is

$$
U(C, L)=\left(C^{\mu}(1-L)^{1-\mu}\right)^{1-\eta} /(1-\eta)
$$

and set $\mu=0.358$, which makes the household supply about $1 / 3$ of the time endowment as labor in the steady state, and $\eta=2$.

I choose the share parameters in production, $\theta=0.5$ and $\alpha=0.35$, so that $50 \%$ of gross output goes to intermediate input expenditures, and $70 \%$ of value-added (gross output net of intermediate expenditures) is paid to labor. The sunk cost of creating a plant, $F_{e}$, shifts levels of variables in the model, but otherwise does not affect anything, so I normalize it to 1.

I choose the distribution over efficiency levels across plants to be Pareto, so that

$$
\begin{aligned}
G(z) & =1-z_{L}^{k} z^{-k} \\
g(z) & =k z_{L}^{k} z^{-k-1}
\end{aligned}
$$

with $z_{L}$ normalized to 1 , and $k>0$.

The parameter $\bar{p}$ is the long-run average price of imports; $\bar{p}$, along with the parameter $k$, which governs heterogeneity in plant efficiencies, and the parameters of the fixed cost function $b$ and $f$, determine the levels and dispersion of import shares and size among importing and nonimporting plants in the model. I choose these four parameters so that a steady state 
of the model with $p_{t}=\bar{p}$ for all $t$ matches averages of moments in Chilean manufacturing plant-level data over the period 1987-1996, as described in the following subsections. I also set $\delta$ to match the average exit rate. From now on, all equilibrium variables with an overbar (e.g. $w_{t}=\bar{w}, \psi_{t}=\bar{\psi}$ ) refer to their values in a steady state.

Table 1: Calibration

\begin{tabular}{lrl}
\hline \hline parameter & value & role \\
\hline$\beta$ & 0.96 & household's discount factor \\
$\mu$ & 0.36 & weight on consumption in utility \\
$\eta$ & 2.00 & intertemporal elasticity of substitution \\
$\theta$ & 0.50 & intermediate share of gross output \\
$\alpha$ & 0.35 & labor share of gross output \\
$F_{e}$ & 1.00 & sunk cost of creating a plant \\
$z_{L}$ & 1.00 & lower bound of distribution of plant efficiences \\
$\delta$ & 0.07 & plant death rate \\
$\bar{p}$ & 0.47 & average price of imports relative to domestic inputs \\
$k$ & 7.96 & shape parameter of Pareto distribution of $z$ \\
$b$ & 0.09 & level parameter in fixed cost function \\
$f$ & 17.53 & curvature parameter in fixed cost function \\
\hline \hline
\end{tabular}

\subsubsection{The distribution of import shares}

Since $z$ is drawn from a Pareto distribution and import shares $n_{t}(z)$ are given by (2), I can characterize the distribution of import shares among importing plants. Ignoring for a moment the constraint that $n \leq 1$, the fraction of importing plants that spend at least a fraction $n$ on imports is:

$$
\begin{aligned}
\operatorname{Pr}\left(n_{t}(z) \geq n \mid z \geq z_{t}^{0}\right) & =\operatorname{Pr}\left(\psi_{t} \log z+\phi_{t} \geq n \mid \psi_{t} \log z+\phi_{t} \geq 0\right) \\
& =\operatorname{Pr}\left(z \geq e^{\left(n-\phi_{t}\right) / \psi_{t}} \mid z \geq e^{-\phi_{t} / \psi_{t}}\right) \\
& =\frac{z_{L}^{k}\left(e^{\left(n-\phi_{t}\right) / \psi_{t}}\right)^{-k}}{z_{L}^{k}\left(e^{-\phi_{t} / \psi_{t}}\right)^{-k}} \\
& =e^{-n k / \psi_{t}}
\end{aligned}
$$

So, including the constraint that the import share cannot exceed one, the overall cumulative distribution function for import shares $n_{t}$ in period $t$ among importing plants is given 
by:

$$
\begin{aligned}
\Gamma_{t}(n) & =\operatorname{Pr}\left(n_{t} \leq n\right) \\
& =\left\{\begin{array}{c}
1-e^{-n k / \psi_{t}} \text { if } n<1 \\
1 \text { if } n \geq 1
\end{array}\right.
\end{aligned}
$$

That is, the distribution $\Gamma_{t}$ has the shape of an exponential distribution with parameter $\frac{k}{\psi_{t}}$ over the range $[0,1)$ and a mass point at 1 , equal to the mass of plants who import all their intermediate goods (those with efficiency at least $z_{t}^{1}$ ).

The distribution of import shares is entirely characterized by the factor $\frac{k}{\psi_{t}}=k\left(\log f+\gamma \log p_{t}\right)$, and so all moments of this distribution are functions of $\frac{k}{\psi_{t}}$. For example, the average import share, $\mu_{n t}$, is given by:

$$
\begin{aligned}
\mu_{n t} & =\int_{0}^{1} n d \Gamma_{t}(n) \\
& =\frac{1}{1-G\left(z_{t}^{0}\right)} \int_{z_{t}^{0}}^{\infty} n_{t}(z) g(z) d z \\
& =\frac{\psi_{t}}{k}\left(1-e^{-k / \psi_{t}}\right)
\end{aligned}
$$

which is negatively related to $k, f$ and $p_{t}$. A higher price of imports $p_{t}$ reduces the benefit of importing, and a higher $f$ raises the fixed cost of importing, so both lower the the expenditure share of all importing plants. A higher $k$ reduces the conditional mean efficiency among importing plants, so also contributes negatively to the average import share.

Matching the steady state average import share in the model to the average in the data pins down the parameter combination $k(\log f+\gamma \log \bar{p})$.

\subsubsection{The dispersion in imports among importers}

For a given import share $n$, a high efficiency plant would be larger than a low efficiency plant, measured by labor used or inputs purchased. But high efficiency plants also choose high import shares. Therefore, the dispersion in heterogeneity in size from the exogenous variation in $z$ is magnified through the dispersion in import shares generated by the shape of the fixed cost function. The relationship between dispersion in size and $f$ is most easily seen in ratios of percentiles of the distribution of imports among importing plants.

Let $z_{q t}$ be the $q$ th percentile of the conditional distribution of efficiencies among plants with nonzero import shares in period $t$, that is, the level above which there are $(100-q) \%$ 
of the importing plants:

$$
\begin{aligned}
\operatorname{Pr}\left(z \geq z_{q t} \mid z \geq z_{t}^{0}\right) & =1-\frac{q}{100} \\
z_{q t} & =\left(z_{t}^{0}\right)\left(1-\frac{q}{100}\right)^{-1 / k}
\end{aligned}
$$

Since total import purchases $M_{t}(z)=n_{t}(z) p_{t} m_{t}\left(z, n_{t}(z)\right)$ are a monotonically nondecreasing function of $z$, the $q$ th percentile of the distribution of imports among importing plants is given by $M_{q t}=M_{t}\left(z_{q}\right)$. As long as $q$ is not so large that $z_{q t} \geq z_{t}^{1}$ (so that the import share for the plant at the $q$ th percentile is interior), this quantity is given by:

$$
\begin{aligned}
M_{q t} & =n_{t}\left(z_{q t}\right) p_{t} m_{t}\left(z_{q t}, n_{t}\left(z_{q t}\right)\right) \\
& =z_{q t} v_{t} \theta\left(\psi_{t} \log z_{q t}+\phi_{t}\right) p_{t}^{-\gamma\left(\psi \log z_{q t}+\phi\right)} \\
& =z_{q t}^{1-\gamma \psi_{t} \log p_{t}} v_{t} \theta\left(\psi_{t} \log z_{q t}+\phi_{t}\right) p_{t}^{-\gamma \phi_{t}}
\end{aligned}
$$

Now, consider the ratio of two percentiles, $q$ and $r$ :

$$
\begin{aligned}
\frac{M_{q t}}{M_{r t}} & =\left(\frac{z_{q t}}{z_{r t}}\right)^{1-\gamma \psi_{t} \log p_{t}} \frac{\psi_{t} \log z_{q t}+\phi_{t}}{\psi_{t} \log z_{r t}+\phi_{t}} \\
& =\left(\frac{100-r}{100-q}\right)^{\frac{1}{k}\left(1-\gamma \psi_{t} \log p_{t}\right)} \frac{\log \left(\frac{100-q}{100}\right)}{\log \left(\frac{100-r}{100}\right)}
\end{aligned}
$$

So given two percentiles of the distribution of imports, their ratio pins down the factor:

$$
\frac{1-\gamma \psi_{t} \log p_{t}}{k}=\frac{\log f}{k\left(\log f+\gamma \log p_{t}\right)}
$$

Given a mean steady state import share $\bar{\mu}_{n}$ which determines $k(\log f+\gamma \log \bar{p})$, the ratio of any two percentiles of the steady state imports distribution, $\frac{\bar{M}_{q}}{\bar{M}_{r}}$, can be used to uniquely identify $f$.

A larger $f$ makes the ratio $\frac{\bar{M}_{q}}{\bar{M}_{r}}$ larger for any two percentiles, $q>r$. For a given dispersion of import shares $\bar{n}(z)$, a larger $f$ makes it more costly for large plants to raise their import ratio, so dispersion in size grows without increasing the dispersion in import shares. 


\subsubsection{The fraction of plants importing}

Plants with efficiency draws above $z_{t}^{0}$ use imported inputs in period $t$. The fraction of plants doing so, $\xi_{t} \in[0,1]$, is:

$$
\begin{aligned}
\xi_{t} & =\operatorname{Pr}\left(z \geq z_{t}^{0}\right) \\
& =z_{L}^{k}\left(z_{t}^{0}\right)^{-k} \\
& =z_{L}^{k} e^{k \phi_{t} / \psi_{t}}
\end{aligned}
$$

With the average import share pinning down the ratio $\frac{k}{\psi}$, a target for $\bar{\xi}$ yields $\bar{\phi}=\bar{\psi} \log \left(\frac{\bar{v} \theta(-\log \bar{p})}{b \log f}\right)$.

\subsubsection{The average size of importing relative to nonimporting plants}

The total expenditures on inputs by a plant with efficiency $z$ are:

$$
\begin{aligned}
X_{t}(z) & =n_{t}(z) p_{t} m_{t}\left(z, n_{t}(z)\right)+\left(1-n_{t}(z)\right) x_{t}\left(z, n_{t}(z)\right) \\
& =z v_{t} \theta p_{t}^{-\gamma n_{t}(z)}
\end{aligned}
$$

The average size of importing plants in the steady state is

$$
\bar{\mu}_{X m}=\frac{1}{1-G\left(z_{t}^{0}\right)} \int_{z_{t}^{0}}^{\infty} z v_{t} \theta p_{t}^{-\gamma n_{t}(z)} g(z) d z
$$

while the average size of nonimporting plants is

$$
\bar{\mu}_{X d}=\frac{1}{G\left(z_{t}^{0}\right)} \int_{z_{t}^{0}}^{\infty} z v_{t} \theta p_{t}^{-\gamma n_{t}(z)} g(z) d z
$$

The ratio of these two can be written (see appendix for derivation):

$$
\frac{\bar{\mu}_{X m}}{\bar{\mu}_{X d}}=\frac{1-\bar{\xi}}{\bar{\xi}} \frac{f e^{-\varsigma_{1}}}{\left(\bar{\xi}^{(1-k) / k}-1\right)}\left(\frac{k-1}{k} \frac{\left(1-\frac{1}{f} e^{\varsigma_{1}}\right)}{\left(\varsigma_{2}-1\right)}+1\right)
$$

where $\bar{\xi}$ is the steady state fraction of plants importing, and $\varsigma_{1}$ and $\varsigma_{2}$ are parameter combinations that are pinned down by the average import share and the ratio of import 
percentiles, as derived above:

$$
\begin{aligned}
\varsigma_{1} & =\frac{k}{\bar{\psi}} \\
\varsigma_{2} & =\frac{1-\gamma \bar{\psi} \log \bar{p}}{k}
\end{aligned}
$$

Therefore, given targets for the first three moments, the ratio of the average size of importing plants relative to nonimporting plants, $\frac{\bar{\mu}_{X m}}{\bar{\mu}_{X d}}$, identifies $k$ through equation (13).

\subsubsection{Chilean Manufacturing Data and Model Fit}

I choose the parameters $\bar{p}, f, k$, and $b$ to match four moments in the model's steady state - average import share, fraction of plants importing, the $75 / 25$ percentile ratio of imports, and the average size of importers relative to nonimporters - to the data from Chile's manufacturing census over the period 1987-1996. ${ }^{4}$ Table 2 displays the data for these moments, along with the fraction of plants exiting each year. I set $\delta$ to match the average exit rate.

Table 2: Chilean Manufacturing Plant Data Moments, 1987-1996

\begin{tabular}{lccccc}
\hline \hline year & $\begin{array}{c}\text { fraction } \\
\text { importing }(\%)\end{array}$ & $\begin{array}{c}\text { average import } \\
\text { share }(\%)\end{array}$ & $75 / 25$ ratio & size ratio & exit rate (\%) \\
\hline 1987 & 24.4 & 33.4 & 16.0 & 6.9 & 8.2 \\
1988 & 23.7 & 31.5 & 13.8 & 4.6 & 7.8 \\
1989 & 21.2 & 31.6 & 16.6 & 4.7 & 6.2 \\
1990 & 20.4 & 32.9 & 13.0 & 4.4 & 5.6 \\
1991 & 21.2 & 32.3 & 13.6 & 4.2 & 5.8 \\
1992 & 23.4 & 33.1 & 15.8 & 3.7 & 6.8 \\
1993 & 24.3 & 33.8 & 14.9 & 3.9 & 6.5 \\
1994 & 26.4 & 33.5 & 17.3 & 4.4 & 8.4 \\
1995 & 23.9 & 34.5 & 16.1 & 4.0 & 8.9 \\
1996 & 24.2 & 33.8 & 17.0 & 4.4 & $\mathrm{n} / \mathrm{a}$ \\
\hline average & 23.3 & 33.0 & 15.4 & 4.5 & 7.1 \\
\hline \hline
\end{tabular}

On average, $23 \%$ of plants report purchasing positive amounts of imported inputs. Among these plants, the average import share is about $33 \%$ of total intermediate input expenditures. The average $75 / 25$ ratio indicates that the importer at the 75 th percentile imports about 15.4 times as much as the importer at the 25th percentile of the distribution of import expenditures. And relative to nonimporting plants, importing plants are on average 4.5

\footnotetext{
${ }^{4}$ The data are from the Encuesta Nacional Industrial Anual, from Chile's Instituto Nactional de Estadistica. These are the data used in Kasahara and Rodrigue (2008), and were described in detail in Liu (1993).
} 
times as large as measured by their total expenditures on intermediate inputs.

The parameters that pin down a $33 \%$ average import share in the model also generate a standard deviation of import shares of 0.29 , compared to the value in the data of $0.27 .^{5}$ In addition, an alternative measure of dispersion of size among importers, the variance of $\log$ imports, is 2.00 in the model, compared to 1.98 in the data. Figures 1 and 2 show the full distributions of the import share and (de-meaned) log imports for each year in the data, along with the model's steady state predictions. Choosing parameters to match the four moments discussed above does a fairly good job at fitting the entire cross-sectional distribution in import shares and size among importers in the data, except that the model generates too many plants who import all their inputs (with an import share of $n=1$ ). Among these plants, there is one less source of heterogeneity in import expenditures, hence the abrupt compression in the model's distribution at the right end of Figure 2.

Figure 1: Cumulative distribution of import expenditure shares

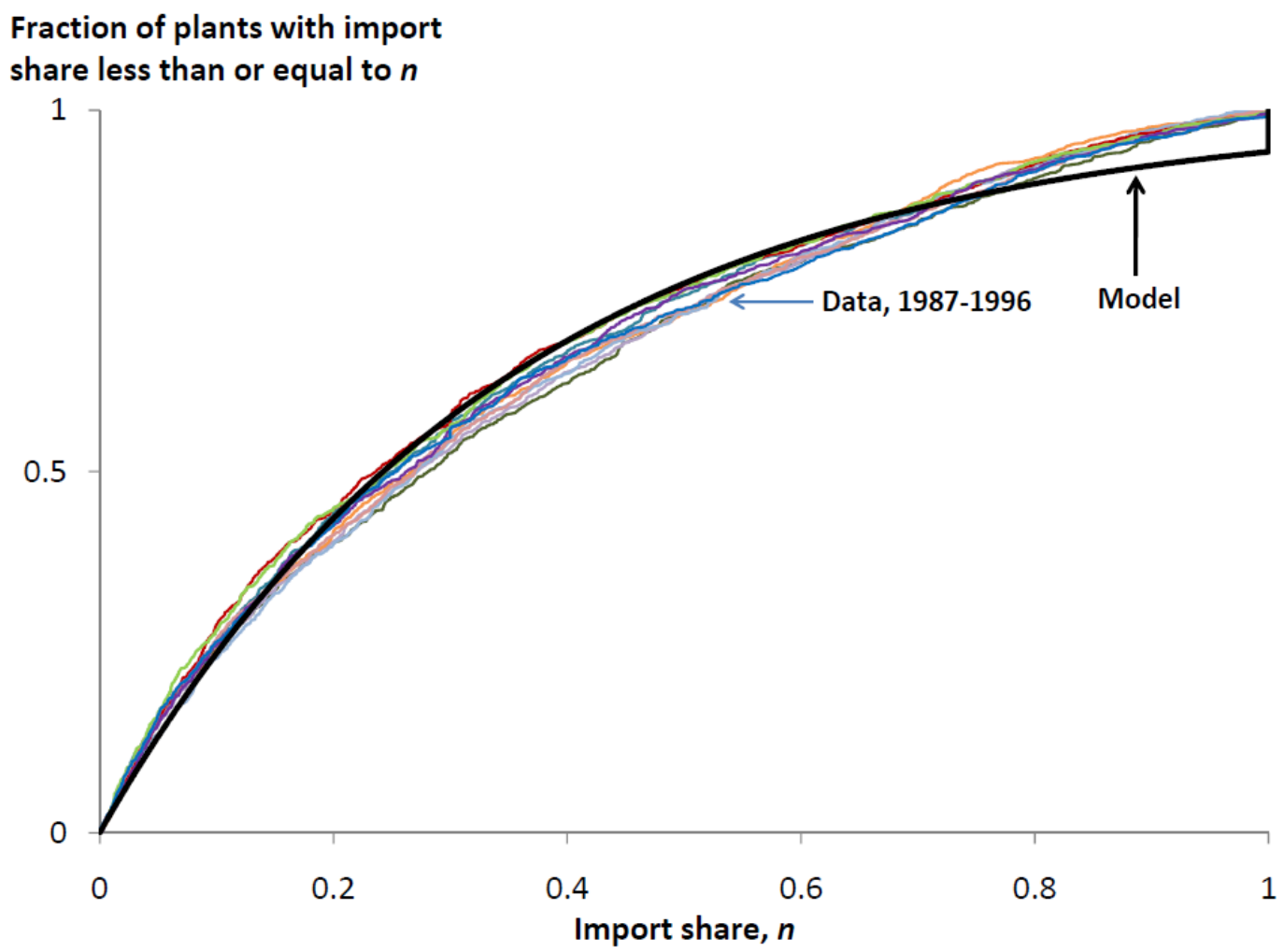

\footnotetext{
${ }^{5}$ If the steady state distribution of $n$ were an untruncated exponential with parameter $k / \bar{\psi}$, then both the mean and standard deviation would be equal to $\bar{\psi} / k$. With the truncation at 1 , the standard deviation is given by

$$
\operatorname{std}(\bar{n}(z))=\left(\frac{2 \bar{\psi}}{k}\left(\frac{\bar{\psi}}{k}-\left(1+\frac{\bar{\psi}}{k}\right) e^{-k / \bar{\psi}}\right)-\bar{\mu}_{n}^{2}\right)^{1 / 2}
$$
}


Figure 2: Cumulative distribution of log imports relative to mean

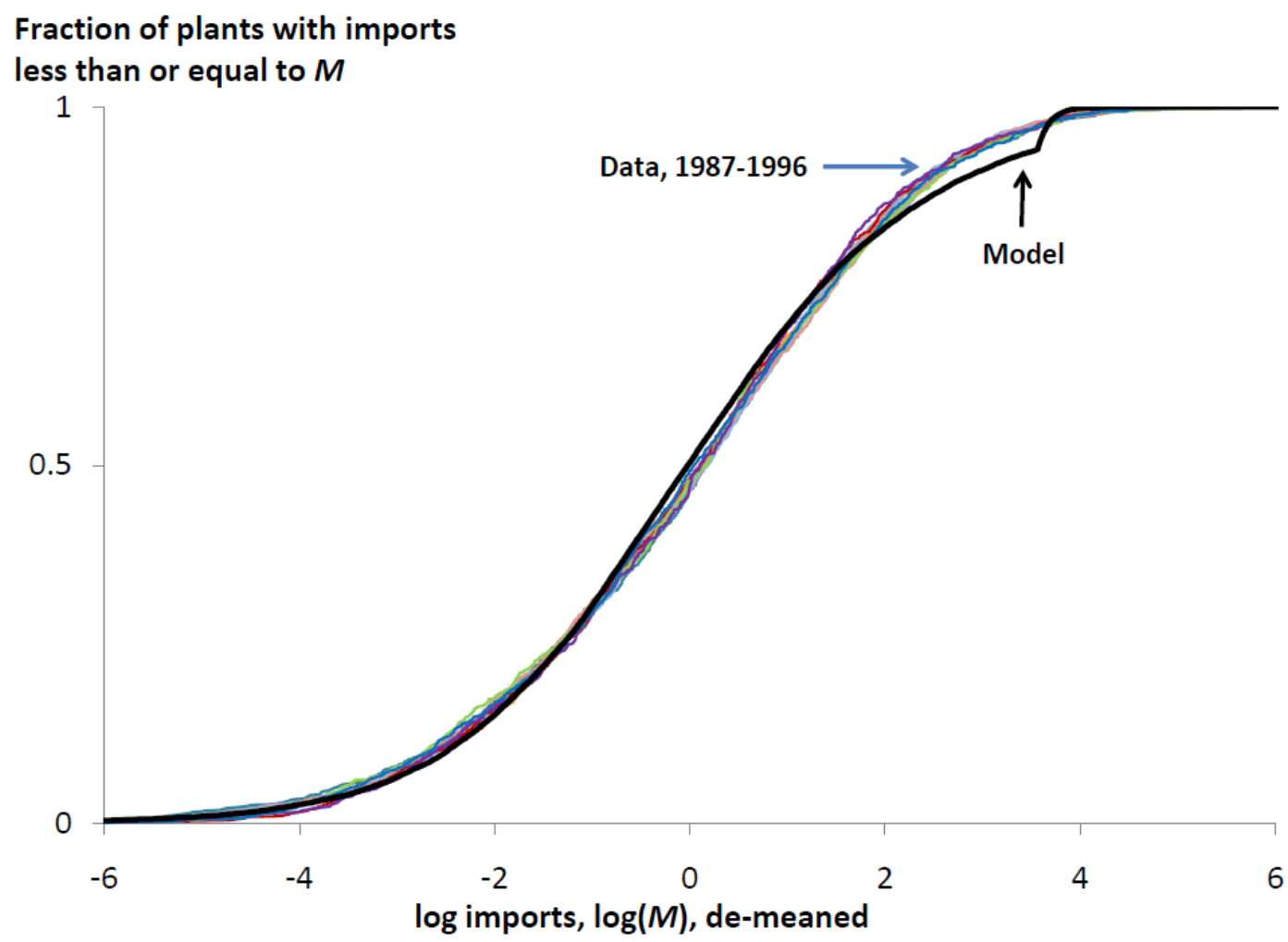

\subsubsection{The productivity advantage of importing}

In my model, plants gain by importing through lowering the price index for the input bundle they purchase. Looking across plants within a period, plants that import a higher share of their inputs appear more productive, even aside from the fact that plants with inherently higher efficiency $z$ have higher import shares. Although calibrated to match moments on heterogeneity in size and import shares (and not productivity measures), my model's structure links the calibrated parameters to an implied gain in productivity from importing.

Several recent empirical studies have estimated this kind of productivity advantage of importing in plant-level data, including Amiti and Konings (2007) using Indonesian data, Halpern, Koren, and Szeidl (2009) using Hungarian data, and Kasahara and Rodrigue (2008) using a subset of the Chilean data considered here. ${ }^{6}$ These papers all estimate production

\footnotetext{
${ }^{6}$ Although they do not estimate the direct producer-level productivity gain from importing, Goldberg, Khandelwal, Pavcnik, and Topalova (2010), using data on Indian firms, find that lower input tariffs, and hence higher expenditures on imported inputs, lead firms to create more new products. They argue that this is because the cost of production decreases (which similar to the increase in productivity considered here), so that producing new products becomes profitable.
} 
functions that relate a plant's output to its factor inputs and intermediate expenditures, along with indicators of whether the plant imports any of its inputs, or its import expenditure share (or both). In my model, the production technology can be represented as:

$$
\log y_{t}=\log z+\alpha \log \ell_{t}+\theta \log x_{t}+n_{t}(z) \log p_{t}^{-\theta}
$$

where $x_{t}$ is a plant's total input expenditures,

$$
x_{t}=n_{t} p_{t} m_{t}+\left(1-n_{t}\right) d_{t}
$$

The percentage gain in productivity for a plant with productivity $z$ that uses imported inputs relative to not using imported inputs (or, equivalently, relative to a plant with the same $z$ who for some reason does not use imported inputs) is given by $n_{t}(z) \log p_{t}^{-\theta}>0$. In the model's calibrated steady state, $\log \bar{p}^{-\theta}=0.38$, which implies that a plant gains $3.8 \%$ in productivity by increasing its import share by 10 percentage points (that is, gains $3.8 \%$ in output given the quantities of all its inputs). The average productivity gain across all importing plants is given by $\bar{\mu}_{n} \log \bar{p}^{-\theta}=0.124$, so that an importing plant on average is $12.4 \%$ more productive than a nonimporting plant, controlling for differences in their exogenous efficiency. Kasahara and Rodrigue (2008) report similar numbers in their analysis of the Chilean plant data. Using a continuous import share variable, their range of estimates imply that raising the import share by 10 percentage points raises productivity by $0.5 \%$ to $2.7 \%$. Using a discrete import status variable, they find that importing raises productivity on average by between $18 \%$ and $21 \%$. Results of similar magnitudes are reported in Halpern, Koren, and Szeidl (2009) and Amiti and Konings (2007).

\subsection{Counterfactual: Unilateral Trade Liberalization}

Starting from the calibrated steady state, I consider a permanent reduction in $p_{t}$ of $10 \%$, which is analogous to a $10 \%$ tariff reduction. I report the effects of this change in the limit as the economy reaches a new steady state.

Looking at the ratio of imports to total intermediate expenditures, trade growth is very large. This ratio is plotted in Figure 3. The new steady state aggregate import ratio is about double the initial value. Within each plant, both the amount spent per imported good and the number of imported goods rises. In addition, plants that were nonimporters switch to importing goods. The long-run elasticity of the import ratio with respect to the $10 \%$ price change is about 10.8 .

This exercise can also be used to measure the productivity benefits of trade liberalization. 
Figure 3: Model Response to 10\% Tariff Reduction

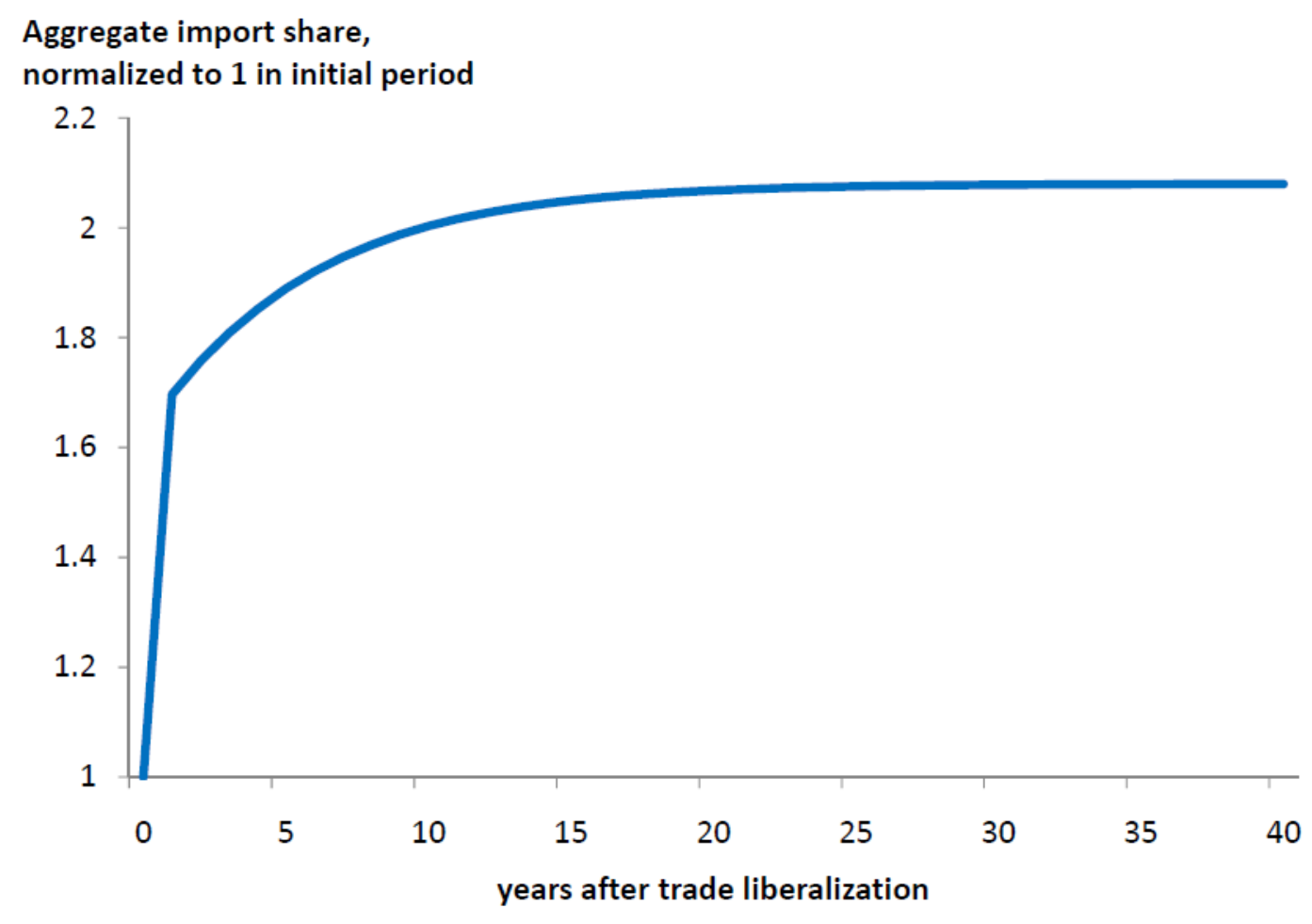

Amiti and Konings (2007) find large within-firm productivity gains in response to input tariff liberalization in their study of Indonesia. In my model, there are two sources of within-plant productivity gains from import price reductions: importing plants purchase their inputs at lower prices, and hence can produce more output with the same amount of expenditure; and both importing and some previously nonimporting plants raise their import shares. In this experiment, the average importing plant experiences a productivity gain of $29 \%$. Overall, the welfare effect of the $10 \%$ import price reduction is a gain of about $5 \%$.

\section{Conclusion}

The model presented here captures the heterogeneity in the use of imported intermediate inputs prevalent in studies of plant- and firm-level data. The model has relatively few parameters that are easily related to observable moments of the data, and accounts for the plant-level productivity gain of importing observed in the data. The model is also useful for counterfactual exercises, and can generate substantial within-plant productivity gains from trade liberalization. Useful extensions would include incorporating both the importing and exporting decisions in a unified model, along the lines of Kasahara and Lapham (2007), and 
embedding the model here in a multi-country setup in which both the production and the purchasing decisions of imported inputs are jointly studied. 


\section{Appendix}

\subsection{Choice of $n$}

A plant with productivity $z$ solves the problem:

$$
\pi_{t}(z)=\max _{n \in[0,1]} \tilde{\pi}_{t}(z, n)-h(n)
$$

The Lagrangian of this problem is:

$$
L=\tilde{\pi}_{t}(z, n)-h(n)+\lambda_{0}(n-0)+\lambda_{1}(1-n)
$$

where $\lambda_{0}, \lambda_{1} \geq 0$, and the first order necessary condition is:

$$
\frac{\partial \tilde{\pi}_{t}(z, n)}{\partial n}-h^{\prime}(n)=\lambda_{1}-\lambda_{0}
$$

where the derivatives are given by:

$$
\begin{aligned}
\frac{\partial \tilde{\pi}_{t}(z, n)}{\partial n} & =z v_{t} \theta p_{t}^{-\gamma n}\left(-\log p_{t}\right) \\
h^{\prime}(n) & =b f^{n} \log f
\end{aligned}
$$

From the complementary slackness conditions $\lambda_{0} n=0$ and $\lambda_{1}(1-n)=0$, it is clear that only one of $\lambda_{0}$ or $\lambda_{1}$ can be positive.

For $\lambda_{0}>0$ and $\lambda_{1}=0, \frac{\partial \tilde{\pi}_{t}(z, n)}{\partial n}<h^{\prime}(n)$, so:

$$
z v_{t} \theta p_{t}^{-\gamma n}\left(-\log p_{t}\right)<b f^{n} \log f
$$

while when $\lambda_{1}>0$ and $\lambda_{0}=0$,

$$
z v_{t} \theta p_{t}^{-\gamma n}\left(-\log p_{t}\right)>b f^{n} \log f
$$

Define two cutoff $z$ levels:

$$
\begin{gathered}
z_{t}^{0}=\frac{b \log f}{v_{t} \theta\left(-\log p_{t}\right)} \\
z_{t}^{1}=\frac{b f \log f}{v_{t} \theta p_{t}^{-\gamma}\left(-\log p_{t}\right)}
\end{gathered}
$$

These come from the first order condition at equality for $n=0$ and $n=1$. Since $z_{t}^{1}=z_{t}^{0} \frac{f}{p_{t}^{-\gamma}}$, $z_{t}^{1}>z_{t}^{0}$ as long as $f>p_{t}^{-\gamma}$, which is the condition assumed in the text. 
Now, for $z<z_{t}^{0}$, the left hand side of the first order condition (15) is:

$$
\begin{aligned}
& z v_{t} \theta p_{t}^{-\gamma n}\left(-\log p_{t}\right)-b f^{n} \log f \\
= & \frac{z}{z_{t}^{0}} b \log f p_{t}^{-\gamma n}-b f^{n} \log f \\
= & b \log f\left(\frac{z}{z_{t}^{0}} p_{t}^{-\gamma n}-f^{n}\right) \\
< & 0 \text { for all } n
\end{aligned}
$$

This implies $\lambda_{0}>0$ (and hence $\lambda_{1}=0$ ), so the optimal $n_{t}(z)=0$.

For $z>z_{t}^{1}$, the left hand side of (15) is:

$$
\begin{aligned}
& z v_{t} \theta p_{t}^{-\gamma n}\left(-\log p_{t}\right)-b f^{n} \log f \\
= & z v_{t} \theta\left(-\log p_{t}\right) f^{n}\left(\frac{p_{t}^{-\gamma}}{f}\right)^{n}\left(1-\frac{z_{t}^{1}}{z}\left(\frac{p_{t}^{-\gamma}}{f}\right)^{1-n}\right) \\
> & z v_{t} \theta\left(-\log p_{t}\right) f^{n}\left(\frac{p_{t}^{-\gamma}}{f}\right)^{n} \\
> & 0 \text { for all } n
\end{aligned}
$$

This implies $\lambda_{1}>0$ (and hence $\lambda_{0}=0$ ), so the optimal $n_{t}(z)=1$.

For $z \in\left(z_{t}^{0}, z_{t}^{1}\right)$, the solution to the first order condition at equality is an interior solution, given by:

$$
z v_{t} \theta p_{t}^{-\gamma n_{t}(z)}\left(-\log p_{t}\right)=b f^{n_{t}(z)} \log f
$$

Taking logs of both sides and rearranging,

$$
n_{t}(z)=\frac{1}{\log f+\gamma \log p_{t}}\left[\log z+\log \left(\frac{v_{t} \theta\left(-\log p_{t}\right)}{b \log f}\right)\right]
$$

which leads to the solution given in (2).

Now, to check the second order condition at this solution, the second derivative of the profit function is:

$$
\begin{aligned}
& \frac{\partial^{2} \tilde{\pi}_{t}(z, n)}{\partial n^{2}}-\frac{\partial^{2} h(n)}{\partial n^{2}} \\
= & \frac{\partial \tilde{\pi}_{t}(z, n)}{\partial n} \log p_{t}^{-\gamma}-b f^{n}(\log f)^{2}
\end{aligned}
$$

For the range where $n$ is interior, I know $\frac{\partial \tilde{\pi}_{t}(z, n)}{\partial n}=b f^{n} \log f$, so the second derivative of 
profit evaluated at the solution is:

$$
\begin{aligned}
& \frac{\partial \tilde{\pi}_{t}(z, n)}{\partial n} \log p_{t}^{-\gamma}-b f^{n}(\log f)^{2} \\
= & b f^{n} \log f\left(\log p_{t}^{-\gamma}-\log f\right) \\
< & 0
\end{aligned}
$$

which is true again by the assumption that $f>p_{t}^{-\gamma}$.

\subsection{Aggregation}

Define the following integral terms:

$$
\begin{aligned}
q_{Y t} & =\int_{z_{L}}^{\infty} z p_{t}^{-\gamma n_{t}(z)} g(z) d z \\
q_{M t} & =\int_{z_{L}}^{\infty} z n_{t}(z) p_{t}^{-\gamma n_{t}(z)} g(z) d z \\
q_{H t} & =\int_{z_{L}}^{\infty} f^{n_{t}(z)} g(z) d z
\end{aligned}
$$

The total amount of plants' labor, domestic inputs, imported inputs, outputs, fixed costs, and profits can be written:

$$
\begin{aligned}
L_{t} & =K_{t} v_{t} \frac{\alpha}{w_{t}} q_{Y t} \\
D_{t} & =K_{t} v_{t} \theta\left(q_{Y t}-q_{M t}\right) \\
M_{t} & =K_{t} v_{t} \theta \frac{1}{p_{t}} q_{M t} \\
Y_{t} & =K_{t} v_{t} q_{Y t} \\
H_{t} & =K_{t} b\left(q_{H t}-1\right) \\
\Pi_{t} & =K_{t} v_{t}(1-\alpha-\theta) q_{Y t}-H_{t}
\end{aligned}
$$

Notice that aggregate profits $\Pi_{t}$ is profits net of fixed costs.

With a Pareto distribution, $g(z)=k z_{L}^{k} z^{-k-1}$, the integral terms $q_{Y t}, q_{M t}, q_{H t}$ can be 
solved:

$$
\begin{aligned}
q_{Y t} & =\int_{z_{L}}^{\infty} z p_{t}^{-\gamma n_{t}(z)} g(z) d z \\
& =\int_{z_{L}}^{z_{t}^{0}} z g(z) d z+\int_{z_{t}^{0}}^{z_{t}^{1}} z p_{t}^{-\gamma\left(\psi_{t} \log z+\phi_{t}\right)} g(z) d z+\int_{z_{t}^{1}}^{\infty} z p_{t}^{-\gamma} g(z) d z \\
& =k z_{L}^{k}\left(\frac{1}{k-1} z_{L}^{1-k}+\left(\left(z_{t}^{0}\right)^{1-k}-p_{t}^{-\gamma}\left(z_{t}^{1}\right)^{1-k}\right)\left(\frac{1}{k+\gamma \psi_{t} \log p_{t}-1}-\frac{1}{k-1}\right)\right)
\end{aligned}
$$

Similarly,

$$
q_{M t}=k z_{L}^{k}\left(\frac{\psi_{t}\left(\left(z_{t}^{0}\right)^{1-k}-p_{t}^{-\gamma}\left(z_{t}^{1}\right)^{1-k}\right)}{\left(k+\gamma \psi_{t} \log p_{t}-1\right)^{2}}-p_{t}^{-\gamma}\left(z_{t}^{1}\right)^{1-k}\left(\frac{1}{k-1+\gamma \psi_{t} \log p_{t}}-\frac{1}{k-1}\right)\right)
$$

and

$$
q_{H t}=1-z_{L}^{k}\left(z_{t}^{0}\right)^{-k}+f z_{L}^{k}\left(z_{t}^{1}\right)^{-k}+k z_{L}^{k} \frac{\left(\left(z_{t}^{0}\right)^{-k}-f\left(z_{t}^{1}\right)^{-k}\right)}{\left(k-\psi_{t} \log f\right)}
$$

\subsection{Average size of importing plants relative to nonimporting plants}

The averages are given by

$$
\begin{aligned}
\bar{\mu}_{X m} & =\frac{1}{1-G\left(\bar{z}^{0}\right)} \int_{\bar{z}^{0}}^{\infty} z \bar{v} \theta \bar{p}^{-\gamma \bar{n}(z)} g(z) d z \\
& =\frac{1}{z_{L}^{k}\left(\bar{z}^{0}\right)^{-k}}\left(\int_{\bar{z}^{0}}^{\bar{z}^{1}} z \bar{v} \theta \bar{p}^{-\gamma(\bar{\psi} \log z+\bar{\phi})} g(z) d z+\int_{\bar{z}^{1}}^{\infty} z \bar{v} \theta \bar{p}^{-\gamma} g(z) d z\right) \\
& =\frac{k}{\left(\bar{z}^{0}\right)^{-k}}\left(\bar{v} \theta \bar{p}^{-\gamma \bar{\phi}} \int_{\bar{z}^{0}}^{\bar{z}^{1}} z^{-\gamma \bar{\psi} \log p-k} d z+\bar{v} \theta \bar{p}^{-\gamma} \int_{\bar{z}^{1}}^{\infty} z^{-k} d z\right) \\
& =\frac{k}{\left(\bar{z}^{0}\right)^{-k}} \bar{v} \theta\left(\bar{p}^{-\gamma \bar{\phi}} \frac{\left(\left(\bar{z}^{1}\right)^{1-\gamma \bar{\psi} \log \bar{p}-k}-\left(\bar{z}^{0}\right)^{1-\gamma \bar{\psi} \log \bar{p}-k}\right)}{1-\gamma \bar{\psi} \log \bar{p}-k}+\bar{p}^{-\gamma} \frac{1}{k-1}\left(\bar{z}^{1}\right)^{1-k}\right)
\end{aligned}
$$

while the average size of nonimporting plants is

$$
\begin{aligned}
\bar{\mu}_{X d} & =\frac{1}{G\left(\bar{z}^{0}\right)} \int_{z_{L}}^{\bar{z}^{0}} z \bar{v} \theta g(z) d z \\
& =\frac{1}{1-z_{L}^{k}\left(\bar{z}^{0}\right)^{-k}} \bar{v} \theta k z_{L}^{k} \frac{1}{1-k}\left(\left(\bar{z}^{0}\right)^{1-k}-z_{L}^{1-k}\right)
\end{aligned}
$$


The ratio of these two is

$$
\frac{\bar{\mu}_{X m}}{\bar{\mu}_{X d}}=\frac{\frac{k}{\left(\bar{z}^{0}\right)^{-k}} \bar{v} \theta\left(\bar{p}^{-\gamma \bar{\phi}} \frac{\left(\left(\bar{z}^{1}\right)^{1-\gamma \bar{\psi} \log \bar{p}-k}-\left(\bar{z}^{0}\right)^{1-\gamma \bar{\psi} \log \bar{p}-k}\right)}{1-\gamma \bar{\psi} \log \bar{p}-k}+\bar{p}^{-\gamma} \frac{1}{k-1}\left(\bar{z}^{1}\right)^{1-k}\right)}{\frac{1}{1-z_{L}^{k}\left(\bar{z}^{0}\right)^{-k}} \bar{v} \theta k z_{L}^{k} \frac{1}{1-k}\left(\left(\bar{z}^{0}\right)^{1-k}-z_{L}^{1-k}\right)}
$$

which can be written:

$\frac{\bar{\mu}_{X m}}{\bar{\mu}_{X d}}=\frac{1-z_{L}^{k}\left(\bar{z}^{0}\right)^{-k}}{z_{L}^{k}\left(\bar{z}^{0}\right)^{-k}} \frac{k-1}{\left(z_{L}^{1-k}-\left(\bar{z}^{0}\right)^{1-k}\right)}\left(\bar{p}^{-\gamma \bar{\phi}} \frac{\left(\left(\bar{z}^{1}\right)^{1-\gamma \bar{\psi} \log \bar{p}-k}-\left(\bar{z}^{0}\right)^{1-\gamma \bar{\psi} \log \bar{p}-k}\right)}{1-\gamma \bar{\psi} \log \bar{p}-k}+\bar{p}^{-\gamma} \frac{1}{k-1}\left(\bar{z}^{1}\right)^{1-k}\right)$

This can be simplified to yield:

$$
\begin{aligned}
\frac{\bar{\mu}_{X m}}{\bar{\mu}_{X d}} & =\frac{1-\bar{\xi}}{\bar{\xi}} \frac{\left(\frac{\bar{z}^{1}}{\bar{z}^{0}}\right)^{1-k}}{\left(\bar{\xi}^{(1-k) / k}-1\right)} \bar{p}^{-\gamma}\left(\bar{p}^{\gamma(1-\bar{\phi})}(k-1)\left(\bar{z}^{1}\right)^{-\gamma \bar{\psi} \log \bar{p}} \frac{\left(1-\left(\frac{\bar{z}^{0}}{\bar{z}^{1}}\right)^{1-\gamma \bar{\psi} \log \bar{p}-k}\right)}{1-\gamma \bar{\psi} \log \bar{p}-k}+1\right) \\
& =\frac{1-\bar{\xi}}{\bar{\xi}} \frac{f e^{-\varsigma_{1}}}{\left(\bar{\xi}^{(1-k) / k}-1\right)}\left(\frac{k-1}{k} \frac{\left(1-\frac{1}{f} e^{\varsigma_{1}}\right)}{\left(\varsigma_{2}-1\right)}+1\right)
\end{aligned}
$$

where the parameter combinations I already know are:

$$
\begin{aligned}
\varsigma_{1} & =\frac{k}{\bar{\psi}} \\
\varsigma_{2} & =\frac{1-\gamma \bar{\psi} \log \bar{p}}{k}
\end{aligned}
$$

and I have used the following:

$$
\begin{aligned}
\bar{\xi} & =z_{L}^{k}\left(\bar{z}^{0}\right)^{-k} \\
\bar{\xi}^{1 / k} & =\frac{z_{L}}{\bar{z}^{0}} \\
\bar{z}^{0} & =e^{-\bar{\phi} / \bar{\psi}} \\
\bar{z}^{1} & =e^{(1-\bar{\phi}) / \bar{\psi}} \\
\bar{\psi} & =\frac{1}{\log f+\gamma \log \bar{p}} \\
e^{1 / \bar{\psi}} & =f \bar{p}^{\gamma}
\end{aligned}
$$

So, given the target $\bar{\xi}$ and some parameter combinations already fixed from other targets, 
I can write $\frac{\bar{\mu}_{X m}}{\bar{\mu}_{X d}}$ as a function of $k$ only. 


\section{References}

Amiti, M., And J. Konings (2007): "Trade Liberalization, Intermediate Inputs, and Productivity: Evidence from Indonesia," American Economic Review, 97(5), 1611-1638.

Arkolakis, C. (2008): "Market Penetration Costs and the New Consumers Margin in International Trade," NBER working paper 14214.

Bernard, A. B., J. B. Jensen, and P. K. Schott (2009): "Importers, Exporters and Multinationals: A Portrait of Firms in the U.S. that Trade Goods," in Producer Dynamics: New Evidence from Micro Data, ed. by T. Dunne, J. B. Jensen, and M. J. Roberts. University of Chicago Press.

Biscourp, P., and F. Kramarz (2007): "Employment, skill structure and international trade: Firm-level evidence for France," Journal of International Economics, 72(1), 22-51.

Chaney, T. (2008): "Distorted Gravity: The Intensive and the Extensive Margins of International Trade," The American Economic Review, 98(4), 1707-1721.

Eaton, J., And S. Kortum (2002): "Technology, Geography and Trade," Econometrica, 70(5), 1741-1779.

EThIER, W. J. (1982): "National and International Returns to Scale in the Modern Theory of International Trade," American Economic Review, 72(3), 389-405.

Goldberg, P. K., A. K. Khandelwal, N. Pavcnik, and P. Topalova (2010): "Imported Intermediate Inputs and Domestic Product Growth: Evidence from India," Quarterly Journal of Economics, 125(4), 1727-1767.

Gopinath, G., and B. Neiman (2011): "Trade Adjustment and Productivity in Large Crises," working paper, Harvard University.

Grossman, G., and E. Helpman (1991): Innovation and Growth in the Global Economy. MIT press, Cambridge, Massachussets.

Grossman, G. M., and E. Helpman (1990): "Comparative Advantage and Long-Run Growth," American Economic Review, 80(4), 796-815.

Halpern, L., M. Koren, And A. Szeidl (2009): "Imported Inputs and Productivity," CeFiG Working Paper 8. 
Kasahara, H., and B. Lapham (2007): "Productivity and the Decision to Import and Export: Theory and Evidence," working paper, University of British Columbia and Queens University.

Kasahara, H., and J. Rodrigue (2008): "Does the Use of Imported Intermediates Increase Productivity? Plant-level Evidence," Journal of Development Economics, 87(1), $106-118$.

Krugman, P., and A. J. Venables (1995): "Globalization and the Inequality of Nations," Quarterly Journal of Economics, 110(4), 857-880.

Kugler, M., and E. Verhoogen (2009): "Plants and Imported Inputs: New Facts and an Interpretation," American Economic Review: Papers and Proceedings, 99(2), 501-507.

Kurz, C. J. (2006): "Outstanding Outsourcers: A Firm-and Plant-Level Analysis of Production Sharing," FEDS Discussion Paper 2006-4.

Liu, L. (1993): "Entry-exit, Learning, and Productivity Change: Evidence from Chile," Journal of Development Economics, 42(2), 217-242.

Melitz, M. J. (2003): "The Impact of Trade on Intra-Industry Reallocations and Aggregate Industry Productivity," Econometrica, 71(6), 1695-1725.

Rivera-Batiz, L. A., and P. M. Romer (1991): "Economic Integration and Endogenous Growth," Quarterly Journal of Economics, 106(2), 531-555.

Romer, P. M. (1990): "Endogenous Technological Change," The Journal of Political Economy, 98(5), S71-S102.

Sanyal, K. K., and R. W. Jones (1982): "The Theory of Trade in Middle Products," American Economic Review, 72(1), 16-31. 